\title{
Aprendizagem baseada em problemas para o ensino de probabilidade no Ensino Médio e a categorização dos erros apresentados pelos alunos
}

\author{
Problem based learning for the teaching of probability in high school and \\ categorization of errors presented by students
}

Sidney Leandro da Silva Viana

Claudia de Oliveira Lozada

\begin{abstract}
Resumo: Neste artigo apresentamos uma pesquisa cujo objetivo foi verificar a efetividade da metodologia ativa de Aprendizagem Baseada em Problemas (ABP) no ensino de Probabilidade no Ensino Médio, com vistas a desenvolver as competências e habilidades previstas na Base Nacional Comum Curricular. Para tanto, procedemos à uma pesquisa qualitativa por meio de um estudo de caso, aplicando uma sequência didática para uma turma de alunos do $2^{\circ}$ ano do Ensino Médio de uma escola pública de Maceió (AL). Para verificar a eficácia da sequência didática e 0 desenvolvimento de competências e habilidades previstas na BNCC, criamos ferramentas de análise para identificação dos tipos de erros e habilidades e competências desenvolvidas. Os resultados mostram a necessidade de os professores conhecerem a ABP para utilizá-la nas aulas, além de compreender que sua aplicação difere em vários aspectos da aplicação no Ensino Superior, havendo a necessidade de adaptá-la para a Educação Básica.
\end{abstract}

Palavras-chave: Metodologias Ativas. Aprendizagem Baseada em Problemas. Ensino de Probabilidade. Competências e Habilidades. Ensino Médio.

Abstract: In this paper we present a research whose objective was to verify the effectiveness of the active methodology of Learning Based on Problems in the teaching of Probability in High School, with a view to developing the competences and abilities foreseen in the Common National Curricular Base. For that, we proceeded to a qualitative research through a case study, applying a didactic sequence to a class of 2nd year High School students from a public school in Maceió (AL). In order to verify the effectiveness of the didactic sequence and the development of competences and skills provided for in the National Common Curricular Base, we created analysis tools to identify the types Sidney Leandro da Silva Viana Licenciando em Matemática pela Universidade Federal de Alagoas (UFAL). Alagoas, Brasil.

D orcid.org/0000-0002-5309-486X

$\bowtie$ sidneyviana_@outlook.com

Claudia de Oliveira Lozada Doutora em Educação. Professora do Programa de Pós-Graduação em Ensino de Ciências e Matemática da Universidade Federal de Alagoas (UFAL). Alagoas, Brasil. iD orcid.org/0000-0003-1425-9956 $\triangle$ clalloz@yahoo.com.br

Recebido em 24/03/2020 Aceito em 27/04/2020 Publicado em 09/05/2020 of errors and skills and competences developed. The results demonstrated the need for teachers to know the PBL to use it in classes, in addition to understanding that its application differs in several aspects from application in Higher Education, with the need to adapt it Basic Education.

Keywords: Active Methodologies. Problem-Based Learning. Teaching Probability. Competencies and Skills. High School. 


\section{Introdução}

Tornar as aulas de Matemática mais dinâmicas estimulando o aluno a interessar-se pelos conteúdos a serem trabalhados tem sido um grande desafio para os professores. As gerações mudaram, sobretudo, com o desenvolvimento científico e tecnológico que colocou à disposição tecnologias móveis que permitem o acesso a um número elevado de informações em poucos segundos, o que modificou a forma de aprender e também de ensinar, além dos novos estilos cognitivos que surgiram (STERNBERG, 1997).

Sendo assim, as formas de abordagem dos conteúdos também se renovaram e o papel das metodologias ativas nesse novo cenário de ambiente de aprendizagem tem sido muito importante porque impulsionou a reconfiguração do planejamento das aulas, colocou em destaque o protagonismo do aluno e acentuou a relevância da mediação por parte do professor nas atividades propostas.

Segundo Moran (2015), as metodologias ativas incorporam a participação ativa dos estudantes no seu aprendizado de maneira híbrida, isto é, as metodologias ativas são o resultado de dois ou mais elementos de aprendizagem, que possibilitam uma maior participação dos alunos. Para se ter uma ideia do que é uma metodologia ativa, é oportuno lembrar de um provérbio chinês que diz: "O que eu ouço, eu esqueço; o que eu vejo, eu lembro; o que eu faço, eu compreendo" (in BARBOSA e MOURA, 2013, p. 54), que foi dito pelo filósofo Confúcio e tem relação direta com a aprendizagem ativa. Silberman (1996) modificou esse provérbio para facilitar a definição que se pretende para as metodologias ativas, dando a ele a seguinte redação: "O que eu ouço, eu esqueço; o que eu ouço e vejo, eu me lembro; o que eu ouço, vejo e discuto, começo a compreender; o que eu ouço, vejo, discuto e faço, eu aprendo, desenvolvendo conhecimento e habilidade; o que eu ensino para alguém, eu domino com maestria" (p. 83).

Essa citação, com a modificação de Silberman (1996), resume os princípios dos métodos ativos de aprendizagem. Se em sua prática de ensino o docente favorecer a mobilização das capacidades de ouvir, ver, perguntar, discutir, fazer e ensinar, ele estará no caminho da aprendizagem ativa, como recomendam Barbosa e Moura (2013).

Mattar (2017) por sua vez, afirma que com a aplicação das metodologias ativas, os alunos tornam-se protagonistas no processo de aprendizagem, e, desta forma, são os principais responsáveis por esse próprio aprendizado. Sendo assim, fica notório que os processos de ensino e de aprendizagem estão centrados unicamente no próprio estudante e o professor assume 0 
papel de mediador (DIESEL, MARCHESAN e MARTINS, 2016).

Embora a afirmação de Mattar (2017) seja recente, é válido acrescentar que a busca por metodologias que fujam do ensino tradicional já é antiga. Paulo Freire, por exemplo, em suas obras sempre defendia uma postura mais ativa dos alunos. Freire (1982) chamava de educação bancária esse estudo, que segue uma tendência tradicional em que os alunos se transformam em vasilhas, que são enchidas de conteúdos pelos professores que fazem com o que eles memorizem e reproduzam os conteúdos, quando forem solicitados. Essa concepção combatida pelo autor se contrapõe à uma educação humanista e problematizadora, que implica diálogo, criticidade e reflexão sobre a realidade.

Assim é que, enquanto a prática bancária, como enfatizamos, implica uma espécie de anestesia, inibindo o poder criador dos educandos, a educação problematizadora, de caráter autenticamente reflexivo, implica num constante ato de desvelamento da realidade. A primeira pretende manter a imersão; a segunda, pelo contrário, busca a emersão das consciências, de que resulte a inserção crítica na realidade. (FREIRE, 1982, p. 80)

Aliado a esse diálogo, Moran (2015) refere-se à essa emersão de consciência como resultado da aplicação de métodos adequados, que têm por objetivo reduzir a pouca participação dos alunos nas aulas, que causam-lhes desinteresse pelos conteúdos abordados pelo professor. Para sustentar essa ideia, Moran (2015) afirma ainda que o professor será responsável por despertar essa consciência e inserção crítica, isto é, o autor orienta que os professores devem promover desafios e atividades que visem mobilizar as potencialidades dos alunos, tais como intelectuais, emocionais e de comunicação.

Para que possamos definir com mais propriedade o que vem a ser metodologias ativas, partimos do que definiu Berbel (2011) quando diz que tais métodos "baseiam-se em formas de desenvolver o processo de aprender, utilizando experiências reais ou simuladas, visando às condições de solucionar, com sucesso, desafios advindos das atividades essenciais da prática social, em diferentes contextos" (p. 29).

Diante disso, pode-se chegar à conclusão que a definição trazida por Berbel (2011) corrobora a sustentação de Moran (2015), de que a utilização das metodologias ativas favorece 0 desenvolvimento da autonomia do aluno no momento em que ele é submetido a atividades que apresentam problematizações de determinadas situações, possibilitando-lhe a liberdade de escolha de estratégias e conteúdos para a resolução dos problemas propostos após uma reflexão, 
estudo e pesquisa, etapas pelas quais o aluno poderá trazer novos elementos que não foram considerados pelo professor em seu planejamento, uma consequência do engajamento do aluno, como ressalta Berbel (2011). Além do mais, as metodologias ativas favorecem o trabalho em equipe e a propositura de problemas reais, importantes para se compreender a aplicação dos conteúdos.

Sendo assim, como afirmam Barbosa e Moura (2013, p. 55), "se a prática de ensino favorecer no aluno as atividades de ouvir, ver, perguntar, discutir, fazer e ensinar, estaremos no caminho da aprendizagem ativa". Há vários tipos de metodologias ativas (MATTAR, 2017), como por exemplo, a sala de aula invertida, a instrução por pares, método do caso, aprendizagem baseada em problemas, entre outras.

A aprendizagem baseada em problemas (ABP), foco deste artigo, pode ser definida como uma metodologia baseada na utilização de problemas para aquisição e integração de novos conhecimentos centrada no aluno (BARROWS, 1986; DESLILE, 2000). É um recurso com potencial para dinamizar as aulas de Matemática, favorecer a participação ativa dos alunos, a tomada de decisão, o trabalho em equipe e 0 aprimoramento das relações interpessoais (O'GRADY et al., 2012).

Para Rodrigues e Figueiredo (1996), nessa metodologia, os conteúdos a serem ensinados e aprendidos devem ser identificados por meio de problemas reais ou simulados, que para serem resolvidos farão com o que os alunos recorram ao que já sabem, integrando esses conhecimentos com os conteúdos de outras disciplinas, desenvolvendo uma pesquisa interdisciplinar. Os autores afirmam ainda que essa integração, quando aliada à prática, permite que se tenha uma maior retenção do conhecimento.

Conforme ressaltam Cyrino e Toralles-Pereira (2004), o diferencial da ABP é a exigência do despertar da criatividade do professor, que não deve estar preocupado com qual conteúdo que 0 aluno deve estar aprendendo, mas sim como e porquê este mesmo aluno aprende. Em particular, no ensino de Matemática, Ribeiro (2008) afirma que uma adoção de metodologia que fuja da prática educacional tradicional que está presente de modo preponderante na sala de aula exige, também, uma transformação no papel do corpo docente e do alunado, se estendendo assim à uma transformação nos processos institucionais e educacionais, como é o caso da inserção da aprendizagem baseada em problemas no currículo.

Para Borochovicius e Tortella (2014), no ensino de Matemática, a prática docente no 
processo de realização da $A B P$ deve se basear em manter as constantes discussões realizadas pelos grupos, guiando essas discussões para a resolução do problema que é proposto e 0 professor tão somente deve intervir quando se fizer necessário estimular o raciocínio crítico dos envolvidos por meio de questionamentos, que tem por objetivo a descoberta de possíveis erros de concepções ou possíveis erros de informações, além de descobrir quais os obstáculos que os alunos enfrentam para encontrar o caminho para solucionar do problema. Segundo esses autores, essa intervenção se dará por meio de uma rápida explicação com exemplos práticos para que brevemente sejam retomadas as discussões pertinentes. Desse modo, estará em direção ao desenvolvimento das competências e habilidades previstas nos documentos oficiais de Educação, como aquelas elencadas na Base Nacional Comum Curricular (BRASIL, 2018).

Além disso, é válido ressaltar as funções do professor na prática da ABP apresentadas por Tomaz (2001). Para ele, o professor deve sempre observar e analisar o andamento do que vem sendo realizado pelos alunos a partir de feedbacks. No uso da ABP, Bridges e Hallinger (1992) recomendam que ao dar o feedback para os alunos, o professor procure explicitar quais os pontos fortes e fracos no trabalho realizado por eles até então, proporcionando uma maior reflexão sobre o que foi desenvolvido e o que precisa melhorar.

Dessa forma, o presente artigo tem como objetivo verificar a efetividade da metodologia de aprendizagem baseada em problemas (ABP) no ensino de Probabilidade no $2^{\circ}$ ano do Ensino Médio, com vistas a desenvolver as competências e habilidades previstas na Base Nacional Comum Curricular (BNCC), por meio da aplicação de uma sequência didática, destacando a criação de categorias de análise e identificação das dificuldades dos alunos durante a aplicação da $A B P$, que será relatada e detalhada a seguir.

\section{A Aprendizagem Baseada em Problemas (ABP): características e diferença em relação à Resolução de Problemas (RP)}

Para que ocorra efetivamente a aprendizagem, deve-se ter ciência que o processo ocorre de uma forma transformacional, como afirma Pereira (1998). Ainda segundo o autor, esse processo acaba exigindo do professor a valorização dos conhecimentos prévios dos alunos, das experiências que ocorrem no cotidiano da turma em que o professor ministra a aula, permitindo, então, a formulação de problemas que tenham por objetivo, estimular, desafiar e incentivar novas aprendizagens, tendo como um dos pilares a contextualização. 
É nesse sentido que, visando auxiliar o aluno no processo de construção do conhecimento teórico da disciplina a ser estudada e no desenvolvimento da capacidade de resolver problemas, como afirma Levin (2001), que surge a Aprendizagem Baseada em Problemas (ABP).

Sabe-se que durante toda a história do sistema educativo, propôs-se diferentes estratégias metodológicas com o propósito de contribuir com o processo educativo, sendo ancoradas por movimentos como o movimento progressista na Educação, que surgiu no final do século XIX. Também conhecido como Escola Nova, esse movimento estimulou o desenvolvimento de práticas de ensino que fossem focadas na aprendizagem, tendo o aluno como centro desse processo. Entre os educadores que contribuíram para esse movimento, pode-se destacar John Dewey, Maria Montessori, Henri Wallon, Célestin Freinet, Lev Vygotsky e Jean Piaget, que buscaram práticas educacionais inovadoras e que se contrapunham ao modelo tradicional de Educação vigente, como afirma Rocha (1988).

É na perspectiva do educador John Dewey que pode-se observar inspiração para 0 surgimento da $A B P$, visto que na teoria pedagógica por ele defendida, a Pedagogia Ativa, propõe que a aprendizagem deve apresentar-se como consequência dos problemas ou situações que propiciam um ambiente duvidoso ou descontentamento intelectual, e isso se deve ao fato que, segundo Cambi (1999), os problemas surgem das experiências reais em que são problematizadas e estimulam a cognição para que ocorra a mobilização das práticas de investigação e resolução criativa dos problemas.

Dewey acreditava que o estímulo cognitivo para o aluno deveria partir de um assunto de natureza não formal, partindo da vivência do próprio aluno, do cotidiano dele, como afirmam Delisle (2000) e O'Grady et al. (2012), que também apontam Dewey como um dos inspiradores da ABP.

Historicamente, o modelo da metodologia de Aprendizagem Baseada em Problemas se expandiu para as escolas de Medicina em todo mundo a partir da inciativa tomada por um conjunto de professores da Universidade de McMaster, no Canadá, no final dos anos 60, como ponderam Souza e Dourado (2015). Ainda segundo os autores, não existe dúvidas da influência de diversos pensadores como Delisle (2000), Savin-Baden e Major (2004), Hill e Smith (2005) e Hillen (2010), que buscaram transformar o ensino e que para isso se propuseram a realizar experiências pedagógicas inovadoras, resultando no que sustenta a Aprendizagem Baseada em Problemas. Esses autores, assim como O'Grady et al. (2012), são unânimes em confirmar a origem dessa metodologia, em 1969, a partir da experiência na Universidade de McMaster, no Canadá, mais 
especificamente na Faculdade de Medicina.

O modelo de ensino proposto pela ABP ganhou grande destaque nos Estados Unidos e nos países Europeus a partir de Howard Barrows, que é apontado como um dos principais articuladores da equipe responsável por pensar o currículo do curso de Medicina em 1966, que fora aplicado oficialmente três anos depois (HILLEN, SCHERPBIER e WIJNEN, 2010). Barrows entendia que para se alcançar os objetivos de desenvolver as capacidades dos alunos de contextualizar os conhecimentos que são adquiridos no âmbito acadêmico de forma teórica, os alunos precisavam também utilizá-lo na sua prática, como afirma Delisle (2000).

Segundo Souza e Dourado (2015), o sucesso do processo de ensino por meio da ABP pode ser justificado por suas características peculiares. Para os autores, a Aprendizagem Baseada em Problemas é um método centrado na aprendizagem, que tem por base investigar para que ocorra a resolução de problemas mais contextualizados e que exige os conhecimentos prévios dos alunos; promove o desenvolvimento das competências necessárias ao trabalho profissional; desenvolve a capacidade crítica na análise dos problemas e na elaboração das soluções; e desenvolve a habilidade de saber avaliar as fontes necessárias utilizadas na investigação, bem como estimula o trabalho cooperativo em grupo.

Ainda segundo esses autores, ao se espalhar pelo mundo, a ABP passou a ser aplicada nas mais variadas áreas do conhecimento, seja da área de Humanas, em cursos como Geografia e Direito, seja na área de Exatas, como Física e Matemática, e até mesmo em Biologia. Foi também adaptada aos mais diversos níveis de Educação, constituindo assim um método bem sistematizado que permitiu aos professores estimular a criatividade dos seus alunos, independente da disciplina que leciona.

Os pesquisadores da Administração Nacional do Espaço e da Aeronáutica, a NASA, definiram em 2001 a ABP como uma estrutura de desenvolvimento curricular e um sistema educacional que não visa envolver somente caminhos para a resolução de problemas, mas também um sistema educacional que possibilita um ambiente de sustento para os conhecimentos adquiridos na disciplina e para as habilidades que são básicas, para colocar os alunos como solucionadores de problemas que estão em consonância com a realidade. Essa definição se sustenta na teoria apresentada por John Dewey de que a inteligência deve ser concebida como um utensílio (DEWEY, 1976), além de descrever as funções da ABP, se fundamentando em Norman e Schmidt (1992). Segundo esses pesquisadores, essa metodologia serve para adquirir 
o conhecimento factual, domínio dos princípios gerais e conceitos que são mobilizados para solucionar problemas.

Para resumir o objetivo dessa metodologia, Menita (1999) apud Bufrem e Sakakima (2003, p. 354) explica que "um dos principais objetivos da ABP é que o estudante adquira a habilidade de acesso e uso de informações de forma independente e cujo aprendizado ele levará para a vida toda". E com isso, destaca que a principal característica da ABP é a apresentação de problemas que ocorrem em determinadas situações em que o aluno se sente curioso a investigar e solucionar.

Como na resolução de problemas (RP), são sugeridos passos para a $A B P$, como colocam Bufrem e Sakakima (2003): leitura e análise do problema, listagem do que é conhecido, relatório do problema (descrição do problema), formulação de objetivos de aprendizagem, listagem de possíveis ações, análise das informações obtidas e apresentação de vereditos e soluções.

Quanto ao processo avaliativo na realização dessa metodologia, Silva (2017) propõe uma avaliação formativa, considerando-se todo o processo do desenvolvimento da ABP com um acompanhamento individualizado.

Queiroz (2012) por sua vez, ressalta a importância do professor tutor, que também é mediador, em considerar dois tipos de avaliação: avaliação pontual — individual, institucional e geralmente somativa - e a processual - formativa, analisando o progresso do aluno nas atividades desempenhadas no grupo - , observando-se como o trabalho em grupo favoreceu a zona de desenvolvimento proximal, além de estimular a capacidade dos alunos de discutir, argumentar, contribuir e ser claro ao apresentar as próprias ideias para resolver o problema proposto. Queiroz (2012) ainda cita o papel dos alunos no grupo que geralmente se alternam entre as funções de coordenador e relator, mas podem eleger ou voluntariamente aceitar ocupar uma dessas funções.

Apesar de todo o histórico de surgimento e os objetivos da Aprendizagem Baseada em Problemas, durante as constantes transformações que ocorreram com passar dos anos no âmbito educativo, essa metodologia é comumente confundida com a Resolução de Problemas, se fazendo necessário a diferenciação para que ocorra a realização adequada da ABP.

Segundo Decker e Bouhuijs (2016), um aspecto que se apresenta como fundamental na análise de semelhanças entre essas duas metodologias é o fato de surgirem de forma bastante ativas, em outras palavras, bastante pragmáticas, independentemente dos contextos em que foram originadas. Esses autores afirmam ainda seu surgimento relacionado as experiências e 
crenças de cunho pessoal de educadores que tinham como objetivo modificar o ensino tradicional dominador em todo o sistema educacional, que se apresentava distante da realidade e de seus problemas.

Nesse sentido, Berbel (1998) entende que a metodologia de Resolução de Problemas (RP) tem como objetivo problematizar a realidade e mobilizar o potencial social, político e ético dos alunos, de modo a participarem ativamente na construção histórica de seu tempo, intervindo na realidade e transformando-a.

Esse propósito é consistente com as proposições que sustentam a pedagogia crítica que, segundo Vila e Vila (2007), possibilita a transformação social por meio de atividades mediatizadas pela realidade em que o aluno está inserido, extraindo assim, o conteúdo de aprendizagem.

O desenvolvimento de habilidades como o pensamento crítico e o aprender a aprender, também sustentam a definição dos objetivos da Aprendizagem Baseada em Problemas, que segundo Barrows e Kelson apud Putman (2001) direcionam os alunos para o desenvolvimento de uma abordagem sistemática para que resolvam problemas da realidade em que estão inseridos, da base ampla de conhecimentos integrados que possam ser aplicados nas mais diferentes situações, da aprendizagem autodirigida, além do desenvolvimento de atitudes para trabalhos em equipe e hábitos de abordar um problema mantendo a aquisição de novos conhecimentos a partir da auto reflexão e auto avaliação.

Apesar das constantes semelhanças entre os objetivos das duas metodologias, observase que ao fazer qualquer levantamento teórico acerca das mesmas, existem trabalhos de diversos autores que consideram a RP superior a $\mathrm{ABP}$ no que se refere ao desenvolvimento de resultados, a citar como exemplo, Cyrino e Toralles-Pereira (2004, p. 785):

\begin{abstract}
A problematização é mais propicia para encorajar os alunos [...] a refletirem sobre a situação global de estudo de uma realidade concreta, com seus conflitos e contradições. Trata-se do estudo da realidade dinâmica e complexa [...]. Ambas ajudam os alunos a reverem seu processo de aprendizagem; todavia, a problematização volta-se com o fito de questionar o quanto determinada experiência mudou a compreensão, a apreensão, as atitudes e o comportamento de cada membro do grupo (alunos e professores), visando à consciência crítica, e não apenas à compreensão dos conceitos e mecanismos básicos da ciência -objeto da ABP. Supera, portanto, o domínio cognitivo do conhecimento.
\end{abstract}

Dessa forma, pode-se ter noção de que numa relação gênero e espécie, a Resolução de Problemas (RP) apresenta-se como a espécie e a Aprendizagem Baseada em Problemas (ABP) 
como um dos gêneros dessa metodologia, como ilustrado a seguir:

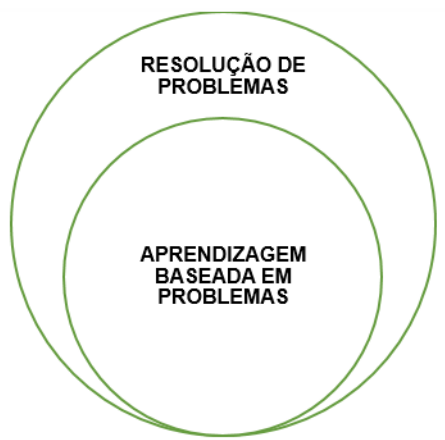

Figura 1: Relação entre a Resolução de Problemas e a Aprendizagem Baseada em Problemas (Elaboração dos Autores)

Desta forma, pode-se afirmar que uma metodologia não exclui a outra, mas que se relacionam de tal forma que a Resolução de Problemas serviu como base para os princípios metodológicos da Aprendizagem Baseada em Problemas, dando oportunidade ao professor de comumente utilizar-se de ambas em sua prática docente, já que como afirmam Decker e Bouhuijs (2016), na RP o professor posiciona-se ao lado do aluno para que ocorra o compartilhamento de suas próprias percepções sobre um problema trazido por ele mesmo, requerendo, como vem destacar Berbel (1998), a aplicação dos conhecimentos e experiências do professor para o auxiliar no desenvolvimento do processo de aprendizagem do aluno, enquanto que na ABP o professor atua como um tutor, estimulando o aluno a encontrar e desenvolver suas próprias estratégias para a resolução de determinados problemas.

Além disso, um outro ponto a ser analisado e diferenciado por ambas as metodologias é a apresentação do problema. Na RP, lembrando as concepções de Freire (1996), a primeira etapa deve servir como condutor para um cenário ou realidade específica, sendo que para o autor, nessa etapa de experiência educativa o aluno irá se confrontar com um problema sem preparação a priori para responder, motivando-o a despertar para a resolução de problema. Freire (1996) denomina essa etapa de "visão ingênua". Em encontro a isso, a ABP consiste em apresentar os problemas de forma em que o problema ainda precise ser definido após a sua apresentação, resultando em uma discussão coletiva sobre o mesmo, dirigindo o foco da atenção dos alunos.

Sendo assim, pode-se notar que apesar dos diferentes caminhos que a RP e a ABP tomam, as duas metodologias apresentam-se as mesmas dificuldades para professores que se dispõem em realizá-las, como ressalta Berbel (1998). Entretanto, é sempre válido recordar que as duas metodologias compartilham de elementos da aprendizagem ativa e contribuem para 0 desenvolvimento da autonomia do aluno. 


\section{Metodologia de pesquisa, instrumentos de coleta e análise de dados}

Esta pesquisa possui uma abordagem qualitativa (MINAYO, 2004), por meio de um estudo de caso, que segundo Lüdke e André (1986) permite estudar uma situação singular. Para tanto, como técnica de pesquisa, foi escolhida a observação participante, técnica esta que, segundo Moreira (2002, p. 52), consiste em "uma estratégia de campo que combina ao mesmo tempo a participação ativa com os sujeitos, a observação intensiva em ambientes naturais, entrevistas abertas informais e análise documental".

Como instrumento de coleta de dados da pesquisa aplicamos uma avaliação diagnóstica, questionário a priori, questionário a posteriori, assim como utilizamos um conjunto de problemas do conteúdo de Probabilidade que constituíram a sequência didática proposta. Os alunos foram divididos em grupos e, para análise dos protocolos de pesquisa - problemas da sequência didática resolvidos pelos alunos —, foram criadas categorias de análise (BARDIN, 1994).

O universo de pesquisa estudado se refere à uma turma do $2^{\circ}$ ano do Ensino Médio de uma escola da rede pública situada no Município de Maceió, no Estado de Alagoas, sendo composta por um grupo com 20 alunos com faixa etária de 16 a 22 anos.

A primeira etapa da pesquisa consistiu na aplicação de um questionário a priori com 16 perguntas; destas, 13 foram designadas com a finalidade de se conhecer e caracterizar o perfil do alunado e as outras três, a fim de identificar os conhecimentos considerados elementares para 0 desenvolvimento do conteúdo de Probabilidade, como também identificar as habilidades que os alunos possuíam para resolver problemas e conceituar termos matemáticos; e, ainda, uma avaliação diagnóstica com três questões, relacionadas aos conhecimentos iniciais sobre Probabilidade.

Em relação ao questionário a posteriori, este possuía 16 questões fechadas que visavam identificar as dificuldades enfrentadas no desenvolvimento do $\mathrm{ABP}$, quais problemas consideraram mais difíceis, se conseguiram compreender a noção de Probabilidade por meio dos problemas propostos e como avaliavam a metodologia de Aprendizagem Baseada em Problemas, aplicada para trabalhar o conteúdo de Probabilidade.

A sequência didática que serviu como instrumento de coleta de dados foi composta por quatro situações-problema, sendo válido ressaltar que nessa pesquisa foi utilizada a classificação de problemas como situações-problema de Dante (1991), em que se buscou alcançar um ambiente de situação de aprendizagem descrito por Lozada e D'Ambrósio (2018), sem que se 
perca a natureza da $A B P$, visto que essa metodologia, com origem voltada para o Ensino Superior, como relatam Silva et al. (2015), tende a propor problemas que não podem ser desenvolvidos no Ensino Básico, se fazendo necessário, na sequência didática proposta, uma adaptação. As situações-problema abrangeram conceitos relacionados ao conteúdo de Probabilidade, descritos no Quadro 1.

Quadro 1: Descrição da Sequência Didática

\begin{tabular}{|c|c|c|c|}
\hline $\begin{array}{l}\text { Tipo de } \\
\text { Atividade }\end{array}$ & $\begin{array}{c}\text { Tempo Estimado Para } \\
\text { Aplicação }\end{array}$ & Conteúdos Abordados & $\begin{array}{c}\text { Conteúdos Matemáticos } \\
\text { Envolvidos }\end{array}$ \\
\hline $\begin{array}{l}\text { Situação- } \\
\text { problema de } \\
\text { natureza } \\
\text { diagnóstica }\end{array}$ & 1 hora/aula & $\begin{array}{l}\text { Frequência Relativa e ideia } \\
\text { inicial de Probabilidade }\end{array}$ & $\begin{array}{l}\text { Operações fundamentais da } \\
\text { Matemática: adição, subtração, } \\
\text { multiplicação e divisão e } \\
\text { porcentagem }\end{array}$ \\
\hline $\begin{array}{l}\text { Situação- } \\
\text { problema sob } \\
\text { enfoque da } \\
\text { ABP }\end{array}$ & 2 horas/aula & $\begin{array}{l}\text { Probabilidades em Espaços } \\
\text { Amostrais Equiprováveis e } \\
\text { Probabilidade Condicional }\end{array}$ & $\begin{array}{c}\text { Operações fundamentais da } \\
\text { Matemática: adição, subtração, } \\
\text { multiplicação e divisão e } \\
\text { porcentagem }\end{array}$ \\
\hline $\begin{array}{l}\text { Situação- } \\
\text { problema sob } \\
\text { enfoque da } \\
\text { ABP }\end{array}$ & 1 hora/aula & $\begin{array}{l}\text { Probabilidade da União de Dois } \\
\text { Eventos e Probabilidade da } \\
\text { Interseção de Dois Eventos }\end{array}$ & $\begin{array}{c}\text { Operações fundamentais da } \\
\text { Matemática: adição, subtração, } \\
\text { multiplicação e divisão; Teoria } \\
\text { dos Conjuntos; Diagrama de } \\
\text { Venn e porcentagem }\end{array}$ \\
\hline $\begin{array}{l}\text { Situação- } \\
\text { problema sob } \\
\text { enfoque da } \\
\text { ABP }\end{array}$ & 2 horas/aula & Probabilidade Geral & $\begin{array}{l}\text { Operações fundamentais da } \\
\text { Matemática: adição, subtração, } \\
\text { multiplicação e divisão }\end{array}$ \\
\hline
\end{tabular}

Fonte: Elaboração dos Autores

A aplicação da sequência didática proposta se deu no mês de novembro de 2019, o que, de certo modo, apresentou alguns obstáculos, visto que esse é um dos meses em que os alunos estão se preparando para as provas finais. Para que os alunos fossem guiados para a Aprendizagem Baseada em Problemas, foram apresentadas sete etapas que serviram para a realização da metodologia.

Tais etapas se basearam nos princípios e características da ABP, bem como nas etapas já sugeridas por Bufrem e Sakakima (2003) e podem servir como orientação tanto para o professor, que propõe o problema, quanto para o aluno que irá respondê-lo. Seguindo essas etapas, a realização da ABP se deu com a organização retratada no Quadro 2. 
Quadro 2: Passos a serem seguidos para a resolução dos problemas propostos pela ABP

\begin{tabular}{|c|c|c|}
\hline Etapa & Ação & Questões \\
\hline $\begin{array}{c}\text { E1 - Leitura e análise } \\
\text { do problema }\end{array}$ & $\begin{array}{l}\text { Identificar os dados apresentados pelos } \\
\text { problemas, destacando o que não se sabe }\end{array}$ & $\begin{array}{l}\text { Quais são os dados? } \\
\text { O que sabemos? } \\
\text { O que não sabemos? }\end{array}$ \\
\hline $\begin{array}{c}\text { E2 - Listagem do que } \\
\text { é conhecido }\end{array}$ & $\begin{array}{c}\text { Registrar, com base nos dados identificados, } \\
\text { quais os conhecimentos prévios que o grupo } \\
\text { possui, questionando e criando as possíveis } \\
\text { soluções para o problema }\end{array}$ & Qual o primeiro passo? \\
\hline $\begin{array}{l}\text { E3 - Descrição do } \\
\text { problema }\end{array}$ & $\begin{array}{c}\text { Descrever o que é desconhecido no } \\
\text { problema, destacando quais as possíveis } \\
\text { estratégias a serem utilizadas }\end{array}$ & $\begin{array}{c}\text { Como podemos resolver isso? } \\
\text { Por quê devemos utilizar esse } \\
\text { conteúdo? }\end{array}$ \\
\hline $\begin{array}{l}\text { E4 - Identificar os } \\
\text { objetivos de } \\
\text { aprendizagem }\end{array}$ & $\begin{array}{l}\text { Listar as necessidades para resolver o } \\
\text { problema, como os novos conceitos e } \\
\text { princípios que devem ser aprendidos }\end{array}$ & $\begin{array}{c}\text { O que falta para responder ao } \\
\text { problema? }\end{array}$ \\
\hline $\begin{array}{l}\text { E5 - Registrar e } \\
\text { realizar as possíveis } \\
\text { estratégias de } \\
\text { resolução }\end{array}$ & $\begin{array}{l}\text { Listar e realizar as estratégias que devem ser } \\
\text { utilizadas, bem como identificar as fontes, } \\
\text { recursos e as ações individuais }\end{array}$ & $\begin{array}{l}\text { Por quê fazer? } \\
\text { Quem faz o quê? }\end{array}$ \\
\hline $\begin{array}{l}\text { E6 - Analisar os } \\
\text { resultados obtidos }\end{array}$ & $\begin{array}{c}\text { Discutir sobre os conhecimentos adquiridos, } \\
\text { revisar os problemas, identificar os novos } \\
\text { problemas que surgiram e testar as hipóteses } \\
\text { criadas }\end{array}$ & $\begin{array}{l}\text { O objetivo foi alcançado? } \\
\text { O que há de novo? }\end{array}$ \\
\hline $\begin{array}{l}\text { E7 - Apresentação } \\
\text { das soluções e } \\
\text { validação }\end{array}$ & $\begin{array}{l}\text { Preparar um registro com as } \\
\text { recomendações, estratégias e uma solução } \\
\text { apropriada para o problema }\end{array}$ & $\begin{array}{l}\text { Essa é a solução? } \\
\text { Por que essa pode ser uma } \\
\text { solução para o problema? }\end{array}$ \\
\hline
\end{tabular}

Fonte: Elaboração dos Autores

As etapas descritas no Quadro 2 serviram como base para a orientação de quais passos da $\mathrm{ABP}$ os alunos deveriam se atentar para que fosse encontrada a resposta correta da situaçãoproblema. Todavia, embora todos os passos da ABP estejam previstos para que se realize a metodologia em sua forma típica, é válido ressaltar que algumas dessas etapas podem ocorrer de diferentes formas: em registro na folha de resposta, de maneira verbal e até mesmo algumas etapas podem ser negligenciadas ou não serem consideradas importantes pelos alunos. Diante disso, o Quadro 3 detalha a forma em que essas etapas poderiam ser realizadas na aplicação de cada situação-problema. 
Quadro 3: Realização dos passos propostos pela ABP

\begin{tabular}{|c|c|c|c|}
\hline $\begin{array}{c}\text { Situação- } \\
\text { problema }\end{array}$ & $\begin{array}{c}\text { Passos da ABP que } \\
\text { devem ser realizados na } \\
\text { forma de registro na folha } \\
\text { de resposta }\end{array}$ & $\begin{array}{c}\text { Passos da ABP que } \\
\text { podem ser realizados } \\
\text { verbalmente }\end{array}$ & $\begin{array}{c}\text { Passos da ABP que } \\
\text { podem ser negligenciados } \\
\text { e/ou considerados não } \\
\text { importantes }\end{array}$ \\
\hline $\begin{array}{c}\text { Situação- } \\
\text { problema 01 } \\
\text { (diagnóstica) }\end{array}$ & E3, E5, E6 e E7 & E1, E2, E3, E4 e E6 & E3, E4, E5, E6 e E7 \\
\hline $\begin{array}{c}\text { Situação- } \\
\text { problema 02 }\end{array}$ & E2, E3, E5, E6 e E7 & E1, E2, E3, E4 e E6 & E3, E4, E5, E6 e E7 \\
\hline $\begin{array}{c}\text { Situaçãa- } \\
\text { problema 03 }\end{array}$ & E2, E3, E5, E6 e E7 & E1, E2, E3 e E4 & E4 e E7 \\
\hline $\begin{array}{c}\text { Situação- } \\
\text { problema 04 }\end{array}$ & E2, E3, E5, E6 e E7 & E1, E3 e E4 & E4 e E7 \\
\hline
\end{tabular}

Fonte: Elaboração dos Autores

No final da aplicação da sequência didática, observando o Quadro 3, constatou-se que os alunos apresentaram bastante dificuldades em realizar os passos sugeridos para a eficiência da $A B P$, que estão listados no Quadro 2, principalmente nas etapas E6 e E7, a de apresentação das soluções e validação, respectivamente, existindo na etapa E7 a possibilidade de os alunos terem a omitido, visto que eles não estavam acostumados com uma metodologia que valorize a etapa de apresentação da validação das respostas, fato que, por muitas vezes, é consequência da ausência de formação docente sobre a abordagem da metodologia como ABP, como reforça Madaime (2018), bem como de outros fatores externos inerentes ao ambiente escolar, sendo preciso uma análise detalhada de como se deu a aplicação de cada situação-problema, como pode ser visto na seção seguinte.

\section{A análise da sequência didática e a categoria de análise}

Mediante a aplicação da sequência didática, ao se recolher os protocolos de pesquisa com a resolução apresentada pelos alunos, foi possivel identificar a influência das práticas pedagógicas nos processos de ensino e de aprendizagem daqueles aqui investigados. Entretanto, ainda que a construção do conhecimento desses alunos sofra com a influência do ensino defasado, se faz necessária uma análise sobre como responderam aos problemas e verificar a efetividade dessa metodologia no grupo estudado. A priori, é válido destacar aqui que os alunos foram divididos em seis grupos, os quais identificamos como G1, G2, G3, G4, G5 e G6, compostos por até 4 
estudantes cada um, que escolheram entre si os seus componentes.

De modo a facilitar a análise das respostas, foram criadas categorias de modo a especificar os resultados obtidos durante a aplicação da sequência didática. Essas categorias foram criadas com base na análise de conteúdo (BARDIN, 1994; MORAES, 1999) como ferramenta de análise de dados e foram criadas seguindo alguns critérios considerados fundamentais na efetividade da metodologia, quais sejam, erros, estratégias de resolução e estratégias de validação. Neste artigo, apresentaremos a categoria dos erros apresentados pelos alunos, conforme Quadro 4.

Quadro 4: Categorização dos erros dos alunos

\begin{tabular}{|c|c|}
\hline Categoria & Aspecto \\
\hline Erro de Ordenação & Erro na interpretação das informações do problema \\
\hline Erro de Argumentação & Erro na ação escolhida e realizada para resolver o problema \\
\hline Erro Sistemático & $\begin{array}{r}\text { Erro no decorrer da estratégia utilizada, podendo ocorrer } \\
\text { principalmente pelas dificuldades no desenvolvimento das quatro } \\
\text { operações fundamentais da Matemática }\end{array}$ \\
\hline Erro de Autenticação & Erro na validação da resposta apresentada \\
\hline Erro Neutro & Não apresentou justificativa para resposta \\
\hline Não apresentação de solução & Não apresentou solução para o problema \\
\hline
\end{tabular}

Fonte: Elaboração dos Autores

No primeiro problema denominado de "Enquete dos Internautas" (Figura 2), o objetivo era que os alunos aprendessem o conteúdo de frequência relativa a um mesmo dado. Neste caso, deveriam responder quantas pessoas responderam "não", e tendo em vista que essa quantidade corresponde a $25 \%$ do número total de entrevistados, bastava calcular $25 \%$ de 279. Dos 6 grupos que estiveram presentes durante a aplicação desse problema, apenas 2 responderam corretamente, o G1 e G3, e dentre os 4 grupos que erraram, metade pode ser classificado como "Não apresentação de solução" para o problema proposto. Além disso, quanto aos outros dois que erraram, o G4 e G5, constatou-se que os erros apresentados pelos alunos se encaixam na categoria de erros de argumentação e erros sistemáticos, respectivamente. Isto é, os alunos apresentam em suas estratégias de resolução dificuldades na realização da ação adotada para resolver o problema. 


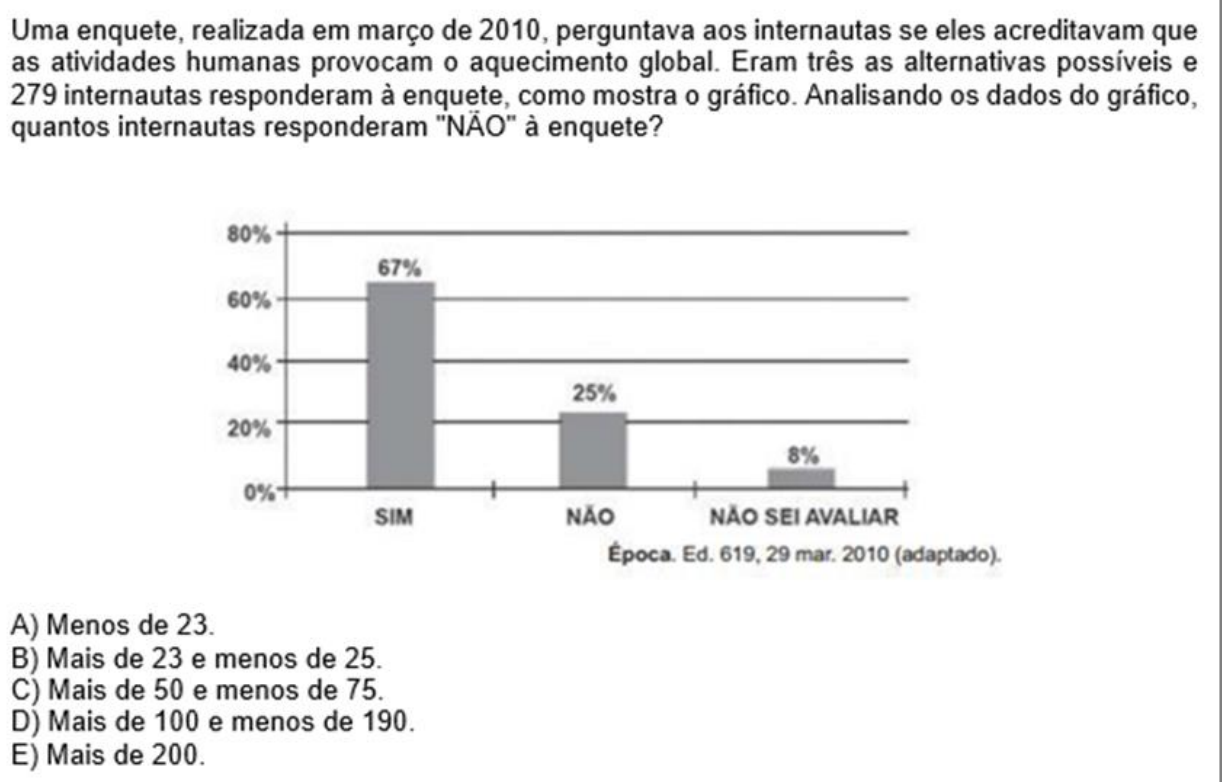

Figura 2: Problema Enquete dos Internautas (Exame Nacional do Ensino Médio, 2011)

Coincidentemente, ou não, ambos os grupos adotaram a divisão como procedimento. Quanto ao G4, não ficou explícito o que os alunos tentaram fazer (ver a Figura 3), induzindo a quem faz a análise desses dados que pensaram primeiramente em dividir o número total de entrevistados por $67 \%$ e, em seguida, obtido o resultado da divisão, dividiram por 0,8, o que hipoteticamente sugere uma falta de atenção já que no enunciado da questão o dado é $8 \%$ e não $80 \%$, como registrado na resolução dos alunos.

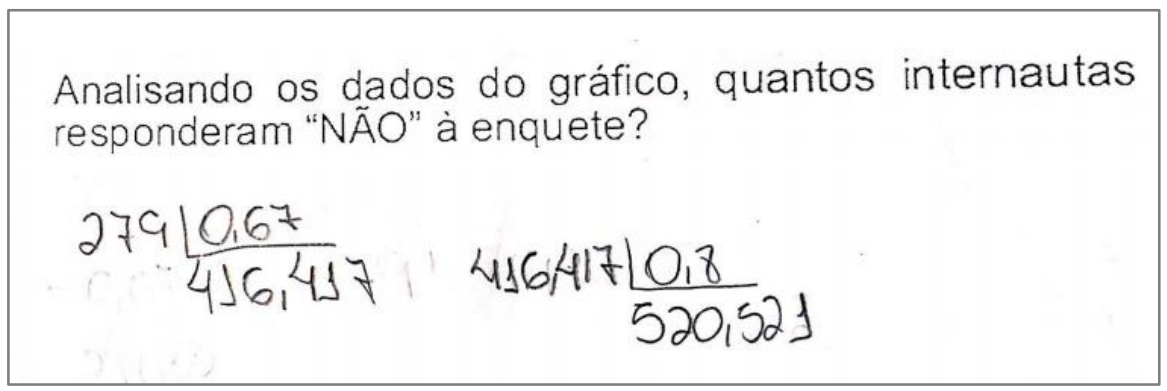

Figura 3: Resolução do G4 para a situação-problema proposta (Dados da Pesquisa)

Além disso, fica evidente que os alunos não fizeram uso dos sete passos sugeridos pela ABP como explicado a eles no início da aplicação da sequência didática. A começar pelo fato de não mostrarem em sua folha de respostas os dados do problema, bem como quais conhecimentos prévios poderiam utilizar. O Quadro 1 mostra que esse problema exigia dos alunos uma certa noção sobre o conteúdo de porcentagem, o que não foi utilizado como estratégia de resolução para o grupo em questão, sendo incluso na categoria de erro de argumentação.

Quanto ao G5, o erro pode ser categorizado como erro sistemático, como mostra a Figura 
4, pois não representaram corretamente o número total de participantes da enquete. Eles consideraram que a população total do problema é a nona parte de 279 , acarretando em um erro sistemático, consequente um erro de ordenação já que não fica explícito para quem analisa o que foi realizado, quais os dados que conseguiram extrair da leitura, interpretação e análise do problema.

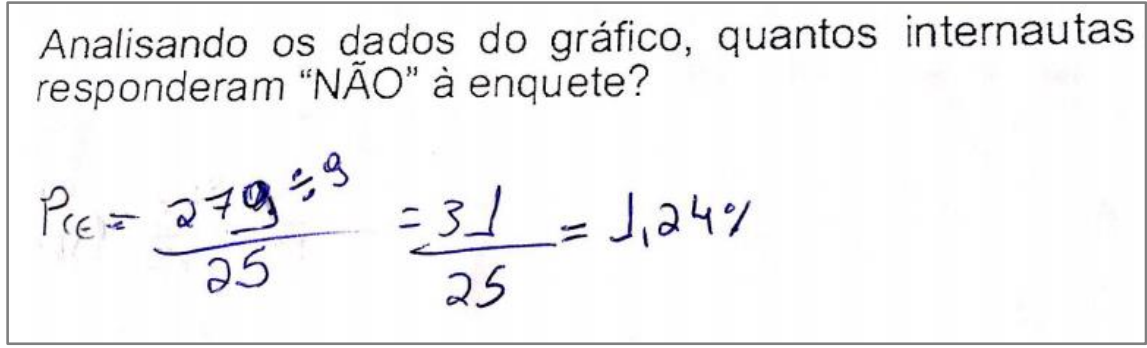

Figura 4: Resolução do G5 para a situação-problema proposta (Dados da Pesquisa)

Na aplicação do segundo problema, denominado de "Contos de Halloween" (Figura 5) um grupo apresentou a folha de resposta sem solução.

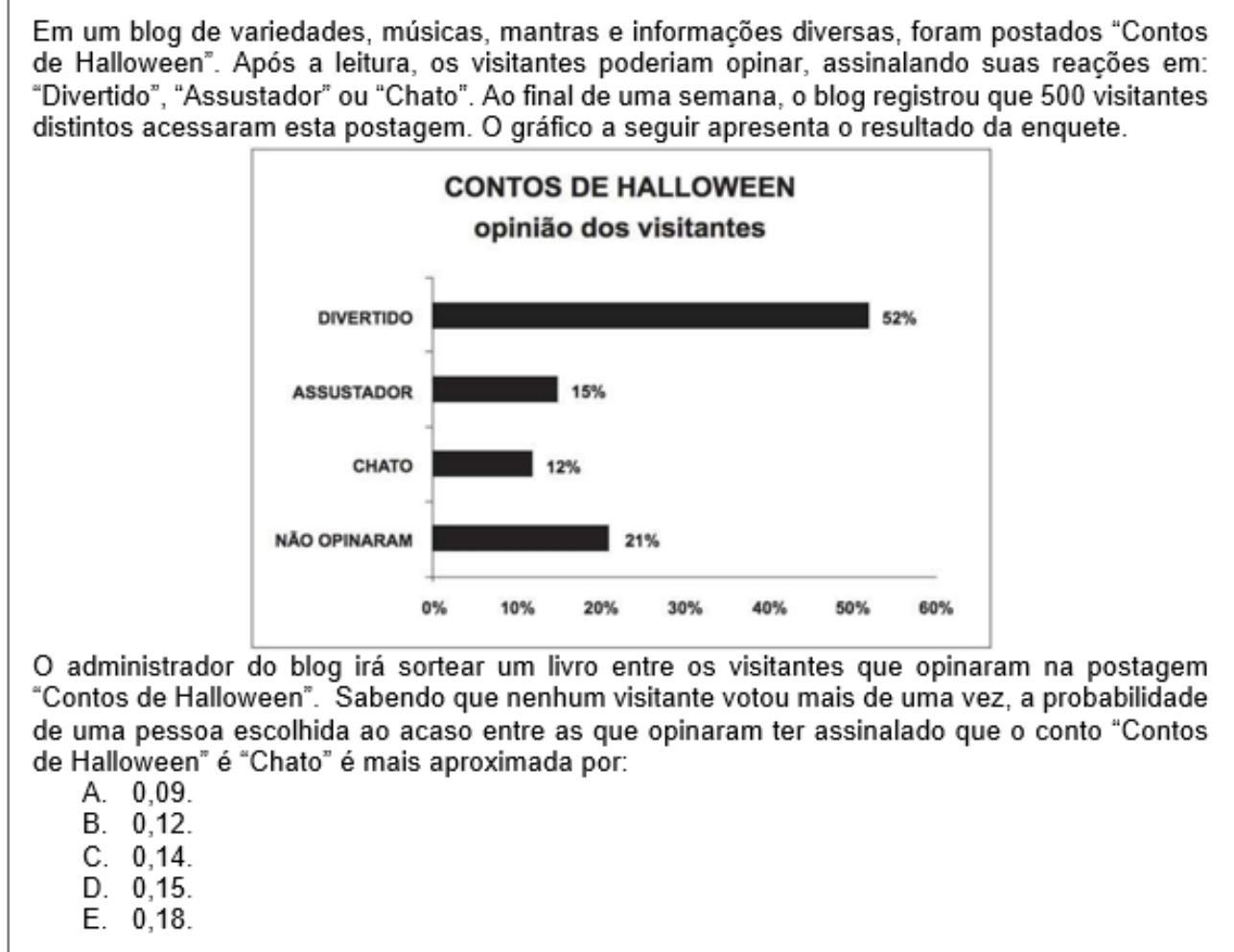

Figura 5: Problema Contos de Halloween (Exame Nacional do Ensino Médio, 2012)

O objetivo desse problema foi a aprendizagem do conteúdo de probabilidade condicional, no qual o espaço amostral a ser considerado deveria ser $79 \%$, já que essa foi a soma do percentual de visitantes que votaram no blog, como no enunciado. A partir daí, os estudantes deveriam 
desenvolver estratégias de resolução a fim de chegar na resposta correta que é $15 \%=0,15$. Se baseando no argumento acima, pôde-se constatar que o erro de todos os grupos se categorizou como erro de ordenação, uma vez que os alunos não entenderam a equivalência entre os espaços amostrais, considerando os $12 \%$ dos casos favoráveis para os $100 \%$ da população total, como pode ser visto nas Figuras 6 e 7.

Sabendo que nenhum visitante votou mais de uma vez, a probabilidade de uma pessoa escolhida ao acaso entre as que opinaram ter assinalado que o conto "Contos de Halloween" é "Chato" é mais aproximada por

A) 0,09 .

$12 \div 100=0,12$

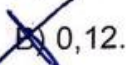

C) 0,14 .

D) 0,15 .

E) 0,18 .

Figura 6: Resolução do G3 para a situação-problema proposta (Dados da Pesquisa)

Sabendo que nenhum visitante votou mais de uma vez, a probabilidade de uma pessoa escolhida ao acaso entre as que opinaram ter assinalado que o conto "Contos de Halloween" é "Chato" é mais aproximada por
A) 0,09 .
$12 \%+10 \div 500$
B) 0,12 .
C. 0,14 .
0,14
D) 0,15 .
E) 0,18 .

Figura 7: Resolução do G2 para a situação-problema proposta (Dados da Pesquisa)

Como se observa na Figura 7, a resolução realizada pelo $\mathrm{G} 2$ foi a única que destoou das demais, que apresentaram como solução 0,12 . Isso se deu por um outro erro classificado aqui como erro de argumentação, já que os alunos dividiram o valor pelo espaço amostral inicial.

Em relação ao terceiro problema, denominado de "União de 2 Eventos", dos seis grupos que participaram da aplicação da sequência didática, todos apresentaram alguma resposta para o problema proposto. Contudo, apenas a metade apresentou a forma de resolução para que fossem analisados os possíveis erros dos alunos no desenvolvimento do problema. Desta forma, as resoluções apresentadas pelos grupos G1, G2 e G6 são categorizadas como erro neutro, segundo o quadro de categorias. 
O problema "União de 2 Eventos" foi extraído de uma prova de concurso público aplicada pela Fundação Getúlio Vargas em 2015 e apresentava o seguinte enunciado: A probabilidade da união de dois eventos, $A$ e B, é conhecida, sendo igual a $80 \%$, enquanto a probabilidade da união de seus complementares é igual a 70\%. Assim, se a probabilidade de A é igual a 40\%, então: a. $P(B)=0,70 ;$ b. $P(B)=0,25 ; c \cdot P(B)=0,30 ; d \cdot P(B)=0,50$; e. $P(B)=0,60$.

Dentre as respostas dadas com alguma espécie de justificativa, observou-se que o G4 errou justamente na escolha da estratégia, caracterizando, assim, erro de argumentação. Como pode ser visto na Figura 6 abaixo, os alunos tentaram aplicar a fórmula de Frequência Relativa, conjecturada e apresentada com base no problema 1, o que induziu o grupo ao erro.

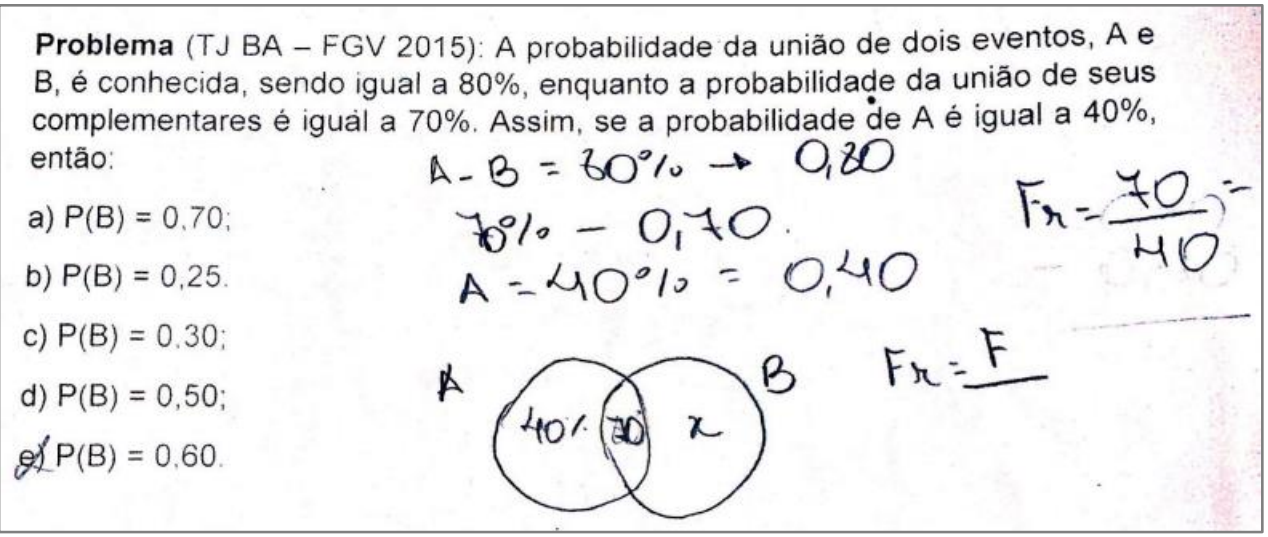

Figura 8: Resolução do G4 para a situação-problema proposta (Dados da Pesquisa)

Da mesma forma que o G4, o G3 também apresentou uma solução errada para 0 problema. Ao analisar quais os motivos levaram os integrantes desse grupo ao erro, constatou-se o de argumentação como sendo o principal. Como pode ser visto na Figura 9, os alunos também fizeram a interpretação de alguns dados de forma errada, explicitando também um erro de ordenação.

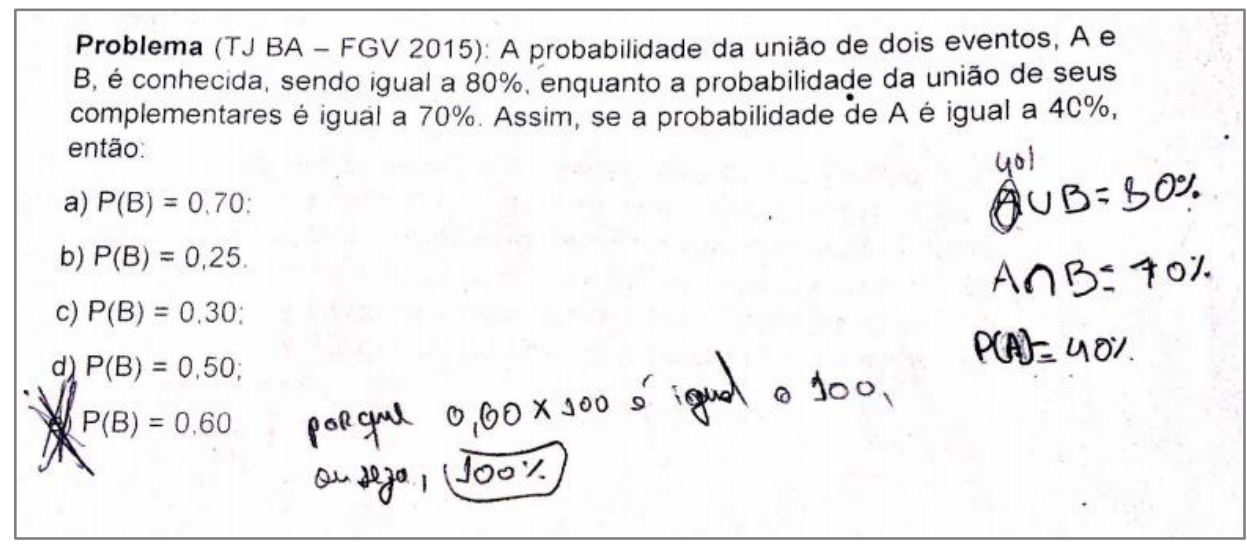

Figura 9: Resolução do G3 para a situação-problema proposta (Dados da Pesquisa) 
Como pode ser visto na Figura 10, para apresentar a resposta 0,60 , os alunos não justificaram a origem desse dado, acarretando na apresentação de uma resposta errada, o que pode ser considerado um "chute" por parte do grupo. Encerrando a análise dos erros apresentados por cada grupo nesse problema, o grupo G5 apresentou erros que podem ser inclusos em todas as categorias elencadas no Quadro 4.

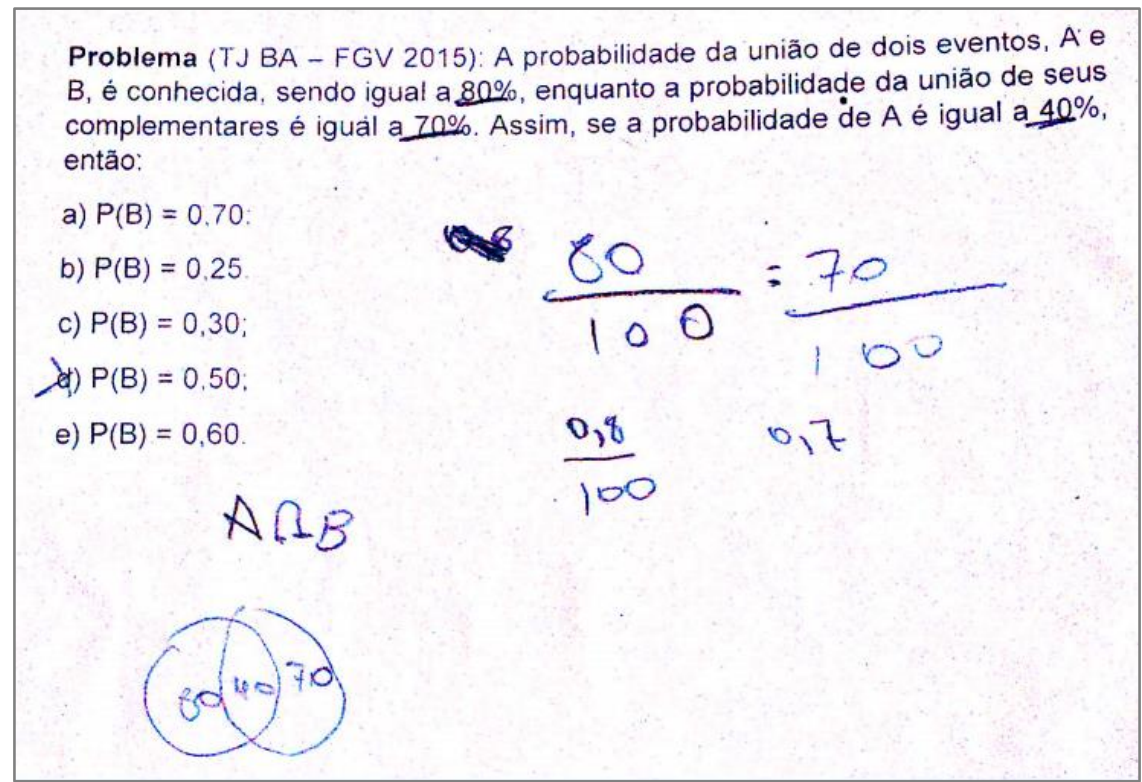

Figura 10: Resolução do G5 para a situação-problema proposta (Dados da Pesquisa)

Como pode ser visto na Figura 10, os alunos não fizeram a ordenação correta dos dados, nem escolheram uma estratégia coerente e ainda apresentaram erros nas operações básicas como a apresentação da equivalência entre as frações. Ademais, é válido destacar aqui que por mais que nenhum grupo tenha conseguido apresentar a resposta correta para o problema, eles buscaram fazer a interpretação utilizando-se dos conhecimentos prévios listados no Quadro 1, principalmente o Diagrama de Venn.

O quarto problema, denominado de "Problema do Baralho" (Figura 11), que pressupunha o acontecimento sucessivo de vários acontecimentos, foi considerado o mais difícil pelos alunos no questionário aplicado posteriormente. Quanto a esse problema, todos os grupos não apresentaram uma resolução para que pudessem ser analisados os seus possíveis erros, pois já estavam entre aqueles que consideraram o problema difícil. 
De um baralho de 28 cartas, sete de cada naipe, Luís recebe cinco cartas: duas de ouros, uma de espadas, uma de copas e uma de paus. Ele mantém consigo as duas cartas de ouros e troca as demais por três cartas escolhidas ao acaso dentre as 23 cartas que tinham ficado no baralho. A probabilidade de, ao final, Luís conseguir cinco cartas de ouros é:
a) $\frac{1}{130}$
b) $\frac{1}{420}$
c) $\frac{10}{1771}$
d) $\frac{25}{7117}$
e) $\frac{52}{8117}$

Figura 11: Problema do Baralho (Fuvest, 2015)

Os alunos não buscaram sequer extrair as informações do problema para que pudessem desenvolver alguma estratégia baseada nas informações. Todavia, o G4 assinalou a alternativa correta e que ainda assim será considerada um erro neutro, por não apresentar a justificativa e, todas as outras resoluções não puderam, aqui, ser categorizadas. Por outro lado, para averiguar indícios de competências e habilidades desenvolvidas, criamos quadros relativos aos quatro problemas propostos com a análise de cada grupo participante. Abaixo, apresentaremos apenas o panorama do G1, dada a limitação de páginas para a redação deste artigo.

O grupo G1, embora não tenha conseguido realizar as etapas da ABP de modo satisfatório para os problemas 3 e 4, no que diz respeito aquelas que podem ser registradas segundo o Quadro 3, e não verificado indícios das competências e habilidades listadas pela BNCC (BRASIL, 2018), apresentou indícios de desenvolvimento das competências 1 e 3 da BNCC relacionadas à utilização de estratégias, conceitos e procedimentos matemáticos para interpretar situações em diversos contextos, analisando a plausibilidade dos resultados e a adequação das soluções propostas, bem como a competência para compreender e utilizar, com flexibilidade e precisão, diferentes registros de representação matemáticos e investigar e estabelecer conjecturas a respeito de diferentes conceitos e propriedades matemáticas, empregando estratégias e recursos, identificando a necessidade, ou não, de uma demonstração cada vez mais formal na validação das referidas conjecturas. 
Quadro 6: Indícios de desenvolvimento das competências e habilidades pelo Grupo 1

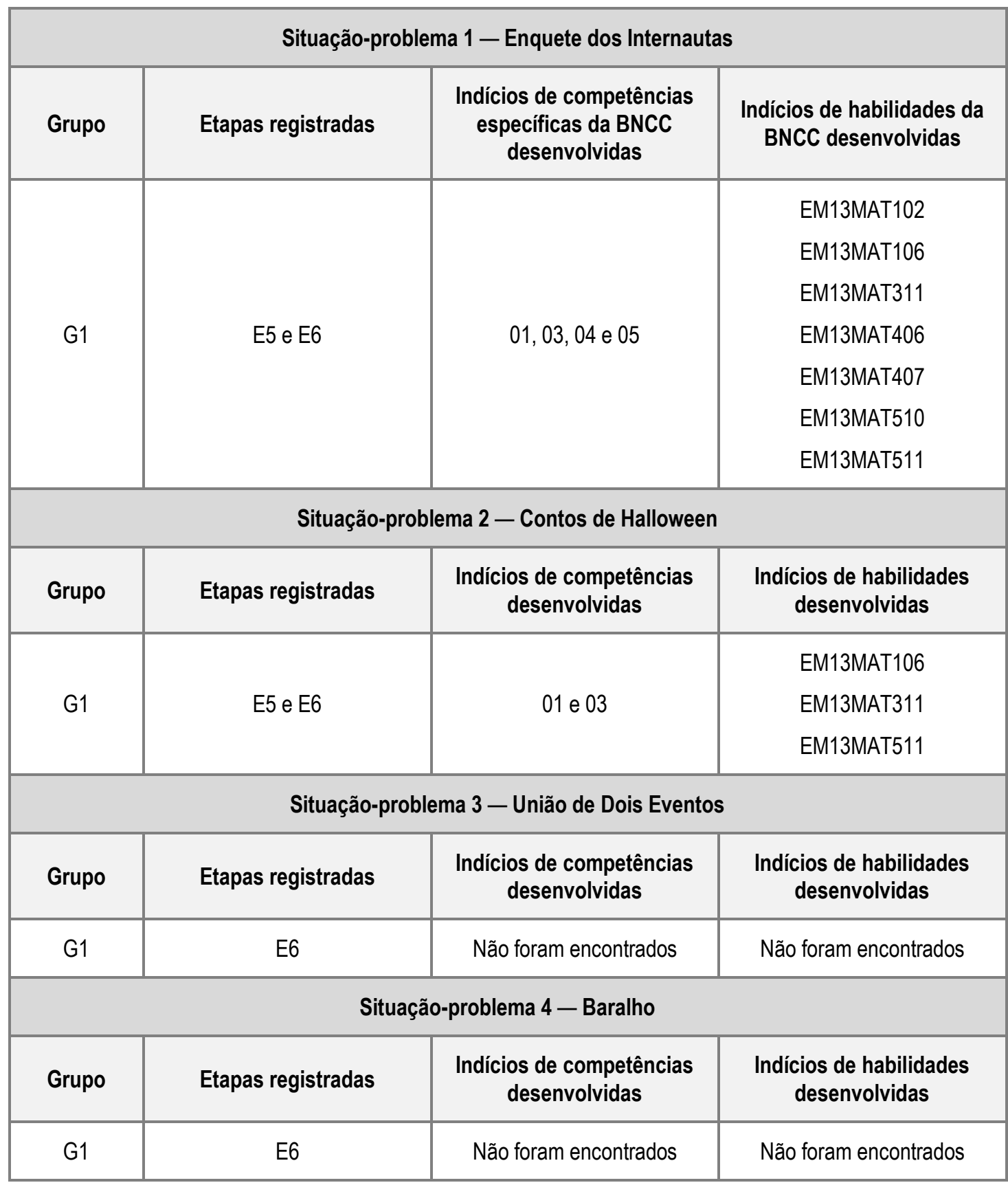

Fonte: Elaboração dos Autores

As habilidades listadas no Quadro 6 - relacionados aos problemas 1 e 2 - se referem à construção, interpretação e análise de gráficos; identificação de situações cotidianas nas quais seja necessário fazer escolhas levando-se em conta os riscos probabilísticos; identificação e descrição do espaço amostral de eventos aleatórios para resolver e elaborar problemas que envolvem o cálculo da probabilidade; investigação sobre conjuntos de dados relativos ao comportamento de duas variáveis numéricas e reconhecimento da existência de diferentes tipos 
de espaços amostrais, discretos ou não, e de eventos, equiprováveis ou não; e investigar implicações no cálculo de probabilidades.

Em relação à realização da $\mathrm{ABP}$, numa escala elaborada de acordo com o número de etapas desenvolvidas, temos: EPNI - execução parcial de nível insatisfatório, realizando 1 ou 2 etapas ( $1^{\mathrm{a}}$ e $2^{\mathrm{a}}$ etapas da ABP ou 1 das outras 5 etapas da ABP); EPNS - realização parcial de nível satisfatório, desenvolvida 2 ou mais etapas dentre a $3^{a}, 4^{a}, 5^{a}, 6^{a}, 7^{a}$ etapas; e ET realização total (todas as etapas).

Para o G1, em relação aos problemas 1 e 2, a realização da ABP pode ser considerada parcial de nível satisfatório e para os problemas 3 e 4, pode ser considerada como parcial de nível insatisfatório, porque só foi desenvolvida uma etapa, no caso a E6. O grupo que teve melhor desempenho na realização da ABP foi o G3 com desenvolvimento parcial de nível satisfatório para os problemas 1, 2 e 3 e com realização parcial de nível insatisfatório para o problema 4 . O G5 teve desempenho similar ao $\mathrm{G} 1$, e os grupos com desempenho aquém do esperado foram o G2, G4 e G6, sendo que este último, o G6, não apresentou registros sobre as etapas para os problemas 1 e 2 e parcial de nível insatisfatório para os problemas 3 e 4. Percebemos que a etapa E7, correspondente à validação da solução do problema, não foi apresentada por nenhum grupo, sendo preciso que o professor habitue os alunos a validarem as soluções, interpretando-as e não as considerando apenas como resultados numéricos que finalizam a resolução.

Os resultados mostram, também, que o professor proponha outros momentos para aplicação de ABP, de modo que tanto docente quanto os alunos sintam-se mais familiarizados com este tipo de metodologia ativa para o ensino de Matemática.

\section{Considerações}

Neste artigo, pudemos observar a importância da formação continuada no sentido de que os professores conheçam novas metodologias de ensino e possam melhorar a prática docente em Matemática.

Hmelo-Silver (2004) coloca que a ABP consiste num aprendizado autodirigido por meio de grupos colaborativos e que possibilita o desenvolvimento de um conhecimento flexível, habilidades efetivas de resolução de problemas, habilidades eficazes de colaboração, motivação intrínseca e habilidades de aprendizagem ao longo da vida, além de desenvolver o pensamento crítico como 
pontua Tiwari et al. (2006). No entanto, é preciso difundi-la nas aulas de Matemática da Educação Básica, o que mostra ser pertinente perceber diferença de abordagem dada no Ensino Superior.

Assim, em relação à aplicação da ABP na Educação Básica, percebemos a necessidade de adaptá-la, dada às características deste nível de escolaridade, além de constatar que algumas etapas podem ser desenvolvidas verbalmente e outras podem ser negligenciadas e/ou consideradas não importantes pelos alunos durante o processo de resolução, o que não descaracteriza a ABP.

A pouca familiaridade em relação à metodologia, evidencia também a necessidade de os professores trabalhar com maior frequência a resolução de problemas, que é uma metodologia fundamental no ensino de Matemática e que de certo modo antecede a ABP, uma vez que as etapas são em número menor e mais abrangentes.

Outro aspecto que se deve pontuar é a validação do resultado e sua respectiva discussão. Os alunos não estão acostumados a essa etapa do processo de resolução, porque em geral esse processo como costumeiramente é realizado nas aulas é visto como algo mecanizado, com fim estritamente numérico, sem discussão sequer desse resultado numérico, o que implica em não proporcionar o desenvolvimento de competências e habilidades ligadas à justificativa e argumentação. Aliás, Dewey (1976), a quem se atribui a base intelectual que fundamenta a ABP, criticava arduamente processos educacionais que implicassem em mecanização de procedimentos e técnicas, ou seja, "aquisição de hábitos mecânicos de pensar e agir" (SOUSA, 2010, p. 242), pois a Educação deve ser norteada por instigar, desafiar e não adestrar. Por outro lado, é importante se trabalhar a leitura e interpretação nas aulas de Matemática, pois os alunos apresentam dificuldades que implicam diretamente na resolução de problemas propostos seja na $A B P$ ou na $R P$, pois muitas vezes, não conseguem relacionar a linguagem cotidiana aos conceitos e ideias matemáticas, como explica D'Antonio (2006).

Além do mais, após identificar os erros dos alunos durante a resolução dos problemas na $A B P$, é preciso dar feedback, trabalhando os erros de modo que os alunos possam observar o que erraram, compreender o caminho adequado, superando assim dificuldade no processo de resolução. $O$ erro faz parte do processo de construção do conhecimento (ESTEBAN, 2001) e não pode ser estigmatizado e relacionado ao fracasso (CURY, 2007), mas sim ser visto como uma dificuldade que precisa ser superada e para isso o professor deve compreender as causas do erro e reconduzir os processos de ensino e de aprendizagem, instrumentalizando suas práticas no 
sentido de possibilitar as aprendizagens dos discentes no percurso formativo, observando as competências e habilidades matemáticas que devem ser desenvolvidas.

Por sua vez, o trabalho em grupo auxilia no desenvolvimento de competências e habilidades socioemocionais, como empatia, autocontrole, assertividade, sociabilidade, tolerância, autonomia, altruísmo, entre outras, importantes para a convivência e o desenvolvimento pessoal.

Outro aspecto a se considerar é explanar com mais ênfase para os alunos as etapas da $A B P$, para que observem haver etapas essenciais no processo de resolução que não podem ser desconsideradas e também para que tenham uma melhor imersão nessa metodologia ativa, evitando confundi-la com a metodologia da resolução de problemas. Também é preciso observar a defasagem de conteúdos básicos de Matemática que precisam ser revisados, pois ancoram conhecimentos subsequentes e afetam o desempenho dos alunos nas atividades propostas.

Numa avaliação global, consideramos uma experiência valiosa a aplicação da ABP para esta turma de alunos do $2^{\circ}$ ano do Ensino Médio, desencadeando uma nova forma de abordagem dos conteúdos e estimulando uma maior participação dos alunos, recomendando que seja aplicada outras vezes, para que se habituem com esta metodologia.

\section{Referências}

BARBOSA, Eduardo Fernandes; MOURA, Décio Guimarães de. Metodologias ativas de aprendizagem na educação profissional e tecnológica. Boletim Técnico do Senac, Rio de Janeiro, v. 39, n. 2, p. 48-67, maio/ago. 2013.

BARDIN, Laurence. Análise de conteúdo. Tradução de Luís Antero Reta e Augusto Pinheiro. Lisboa: Edições 70, 1994.

BARROWS, Howard S. A taxonomy of Problem-Based Learning methods. Medical Education, v. 20, n. 6, p. 481-486, nov. 1986.

BERBEL, Neusi Aparecida Navas. As metodologias ativas na promoção da autonomia de estudantes. Semina: Ciências Sociais e Humanas, Londrina, v. 32, n. 1, p. 25-40, 2011.

BERBEL, Neusi Aparecida Navas. Metodologia da problematização: experiências com questões de ensino superior. Londrina: EdUEL, 1998.

BOROCHOVICIUS, Eli; TORTELLA, Jussara Cristina Barboza. Aprendizagem Baseada em Problemas: um método de ensino-aprendizagem e suas práticas educativas. Ensaio: Avaliação e Políticas Públicas em Educação, Rio de Janeiro, v. 22, n. 83, p. 263-294, abr.jun. 2014.

BRASIL. Ministério da Educação. Secretaria de Educação Básica. Base Nacional Comum 
Curricular. Ensino Médio. Brasília: MEC/SEB, 2018.

BRIDGES, Edwin M.; HALLINGER, Phillip. Problem based learning for administrators. Oregon: ERIC Clearinghouse on Educational Management, 1992.

BUFREM, Leilah Santiago; SAKAKIMA, Andréia Massamí. O ensino, a pesquisa e a aprendizagem baseada em problemas. Transinformação, Campinas, v.15, n. 3, p. 351-361, set./dez. 2003

CAMBI, Franco. História da Pedagogia. São Paulo: EdUNESP, 1999.

CURY, Helena Noronha. Análise de erros: o que podemos aprender com as respostas dos alunos. Belo Horizonte: Autêntica, 2007.

CYRINO, Eliana Goldfarb; TORALLES-PEREIRA, Maria Lúcia. Trabalhando com estratégias de ensino-aprendizado por descoberta na área da saúde: a problematização e a aprendizagem baseada em problemas. Cadernos de Saúde Pública, Rio de Janeiro, n. 20. v. 3, p. 780-788, maio/jun. 2004.

DANTE, Luis Roberto. Didática da resolução de problemas de Matemática 3. ed. São Paulo: Ática, 1991.

D'ANTONIO, Sandra Regina. Linguagem e Matemática: uma relação conflituosa no ensino? 2006. 188f. Dissertação (Mestrado em Educação para a Ciência e o Ensino de Matemática) - Centro de Ciências Exatas. Universidade Estadual de Maringá. Maringá.

DECKER, Isonir da Rosa; BOUHUIJS, Peter A. J. Aprendizagem baseada em problemas e metodologia da problematização: identificando e analisando continuidades e descontinuidades nos processos de ensino-aprendizagem. In: ARAÚJO, Ulisses Ferreira; SASTRE, Genoveva. (Org.). Aprendizagem baseada em problemas no ensino superior. São Paulo: Sumus, 2016, p. 177-204.

DELISLE, Robert. Como realizar a aprendizagem baseada em problemas. Porto: ASA, 2000.

DEWEY, John. Experiência e Educação. Tradução de Anísio Teixeira. 2. ed. São Paulo: Companhia Editora Nacional, 1976.

DIESEL, Aline; MARCHESAN, Michele Roos; MARTINS, Silvana Neumann. Metodologias ativas de ensino na sala de aula: um olhar de docentes da educação profissional técnica de nível médio. Signos, Lajeado, v. 37, n. 1, p. 153-169, jan./jun. 2016.

ESTEBAN, Maria Teresa. O que sabe quem erra? Reflexões sobre avaliação e fracasso escolar. Rio de Janeiro: DP\&A, 2001.

FREIRE, Paulo. Ação cultural para a liberdade e outros escritos. 6. ed. Rio de Janeiro: Paz e Terra, 1982.

FREIRE, Paulo. Pedagogia da autonomia: saberes necessários à prática educativa. 25. ed. São Paulo: Paz e Terra, 1996.

HILL, Ann Marie.; SMITH, Howard A. Problem-based contextualized learning. In: ALSOP, Steve; BENCZE, Larry; PEDRETTI, Erminia. (Ed.). Analysing exemplary science teaching: theoretical 
lenses and a spectrum of possibilities for practice. London: Open University Press, 2005, p. 136145.

HILLEN, Harry; SCHERPBIER, Albert; WIJNEN, Wynand. History of problem-based learning in medical education. In: BERKEL, Henk van.; SCHERPBIER, Albert; HILLEN, Harry; VLEUTEN, Cees van der. (Ed.). Lessons from problem-based learning. New York: Oxford University Press, 2010, p. 5-12.

HMELO-SILVER, Cindy E. Problem-Based Learning: what and how do students learn? Educational Psychology Review, v.16, n.3, p. 235-266, 2004.

LEVIN, Barbara B. (Ed). Energizing teacher education and professional development with problembased learning. Alexandria: ASCD, 2001.

LOZADA, Claudia de Oliveira; D'AMBROSIO, Ubiratan. Considerações sobre o conceito de equação presente nos cadernos do professor e as zonas de perfil conceitual de equação. Revista Paranaense de Educação Matemática, Campo Mourão, v. 7, n. 14, p. 7-38, jul./dez. 2018.

LÜDKE, Menga; ANDRÉ, Marli. Pesquisa em Educação: abordagens qualitativas. São Paulo: EPU, 1986.

MADAIME, Gabriela Finco. Aprendizagem baseada em problemas no Ensino Fundamental II: aplicabilidade, potencial e reflexões de uma adaptação sob perspectivas geocientíficas. 2018. 245f. Tese (Doutorado em Ensino de Ciências e Matemática) — Instituto de Física. Universidade Estadual de Campinas. Campinas.

MATTAR, João. Metodologias ativas para a educação presencial, blended e à distância. São Paulo: Artesanato Educacional, 2017.

MINAYO, Maria Cecília de Souza. O desafio do conhecimento: pesquisa qualitativa em saúde. 8. ed. São Paulo: HUCITEC, 2004.

MORAES, Roque. Análise de conteúdo. Educação, Porto Alegre, v. 37, p. 7-32, 1999.

MORAN, José Manuel. A educação que desejamos: novos desafios e como chegar lá. Campinas: Papirus, 2015.

MOREIRA, Daniel Augusto. O método fenomenológico na pesquisa. São Paulo: Pioneira Thomson, 2002.

NORMAM, Geoffrey R.; SCHMIDT, Henk G. The psychological basis of problem-based learning: a review of the evidence. Acad Med, v. 67, n. 9, p. 557-565, sep. 1992.

O'GRADY, Glen; YEW, Elaine; GOH, Karen; SCHMIDT, Henk. (Ed.). One-day, one-problem: an approach to problem-based learning. Singapore: Springer, 2012.

PEREIRA, Elisabete Monteiro de Aguiar. Professor como pesquisador: o enfoque da pesquisaação na prática docente. In: GERALDI, Corinta Maria Grisolia; FIORENTINI, Dario; PEREIRA, Elisabete Monteiro de Aguiar. (Org.). Cartografias do trabalho docente: professor(a) pesquisador(a). Campinas: Mercado de Letras, 1998, p. 153-181. 
PUTNAN, Alvim R. Problem-based teaching and learning in technology education. In: ANNUAL CONFERENCE OF THE ASSOCIATION FOR CAREER AND TECHNICAL EDUCATION, 75th, 2001, New Orleans. Washington: ERIC, 2001, p. 3-14.

QUEIROZ, Anabela. PBL, problemas que trazem soluções. Revista Psicologia, Diversidade e Saúde, Salvador, v. 1, n. 1, p. 26-38, dez. 2012.

RIBEIRO, Luis Roberto de Camargo. Aprendizagem baseada em problema: PBL uma experiência no Ensino Superior. São Carlos: EduFSCar, 2008.

ROCHA, Filipe. Correntes pedagógicas contemporâneas. Aveiro: Editora Estante, 1988.

RODRIGUES, Maria de Lourdes Veronese; FIGUEIREDO, José Fernando de Castro. Aprendizado centrado em problemas. Medicina, Ribeirão Preto, v. 29, p. 396-402, out./dez. 1996.

SAVIN-BADEN, Maggi; MAJOR, Claire Howell. Foundations of problem-based learning. New York: Open University Press, 2004.

SILBERMAN, Mel L. Active learning: 101 strategies do teach any subject. Boston: Allyn and Bacon, 1996.

SILVA, Fabiana Carvalho. Proposta de avaliação formativa aplicando aprendizagem baseada em problemas (ABP) no Ensino Médio. 2017. 78f. Dissertação (Mestrado em Projeto de Ciências) Escola de Engenharia de Lorena. Universidade de São Paulo. Lorena.

SILVA, Sonia Leite da. et al. Estratégia educacional baseada em problemas para grandes grupos: relato de experiência. Revista Brasileira de Educação Médica, Rio de Janeiro, v. 39, n. 4, p. 607613, out./dez. 2015.

SOUSA, Sidnei de Oliveira. Aprendizagem baseada em problemas como estratégia para promover a inserção transformadora na sociedade. Acta Scientiarum Education, Maringá, v. 32, n. 2, p. $237-$ 245, jul./dez. 2010.

SOUZA, Samir Cristino de; DOURADO, Luis. Aprendizagem baseada em problemas (ABP): um método de aprendizagem inovador para o ensino educativo. Holos, Natal, v. 31, v. 5, p. 182-200, 2015.

STERNBERG, Robert J. Thinking styles. New York: Cambridge University Press, 1997.

TIWARI, Agnes; LAI, Patrick; SO, Mike; YUEN, Kwan. A comparison of the effects of problembased learning and lecturing on the development of students' critical thinking. Medical Education, v. 40, n. 6 , p. $547-554,2006$.

TOMAZ, José Batista Cisne. O desenho de currículo. In: MAMEDE, Silvia; PENAFORTE, Julio Cesar. (Org.). Aprendizagem baseada em problemas: anatomia de uma nova abordagem educacional. Fortaleza: Hucitec, 2001, p. 109-139.

VILA, Ana Carolina Dias; VILA, Vanessa da Silva Carvalho. Tendências da produção do conhecimento na Educação em Saúde no Brasil. Revista Latino-Americana de Enfermagem, Ribeirão Preto, v. 15, n. 6, p. 1177-1183, dez. 2007. 